\title{
BMJ Open A cross-sectional study on health-related knowledge and its predictors among Chinese vocational college students
}

\author{
Weina Wang, ${ }^{1,2}$ Yanli Hou, ${ }^{2}$ Nan Hu, ${ }^{1,2}$ Dongxian Zhang, ${ }^{2}$ Junliang Tao, ${ }^{1,2}$ \\ Yonghong Man, ${ }^{1,2}$ Aimei Wang, ${ }^{1,2}$ Ling $\mathrm{Li}^{1,2}$ Yongyi Bi ${ }^{1}$
}

To cite: Wang W, Hou Y, $\mathrm{Hu} \mathrm{N}$, et al. A cross-sectional study on health-related knowledge and its predictors among Chinese vocational college students. BMJ Open 2014;4:e005182.

doi:10.1136/bmjopen-2014005182

- Prepublication history for this paper is available online. To view these files please visit the journal online (http://dx.doi.org/10.1136/ bmjopen-2014-005182).

Received 13 May 2014 Accepted 29 August 2014

CrossMark

\begin{abstract}
${ }^{1}$ Wuhan University School of Public Health, Wuhan, China ${ }^{2}$ Nanyang Medical College, Nanyang, China
\end{abstract}

Correspondence to Dr Yongyi Bi; yongyibi3214@yeah.net

\section{ABSTRACT}

Objectives: This study sought to examine the level of health-related knowledge and its predictors among vocational college students in China.

Study design: A cross-sectional study.

Methods: A survey was performed to collect data on heath-related knowledge and potential risk factors among 708 students in four higher vocational colleges at Nanyang, Henan, China. Linear regression models were conducted to identify the predictors of the level of health-related knowledge.

Results: The level of health-related knowledge among Chinese vocational college students is extremely low (only 1.4\% students have an adequate level of healthrelated knowledge). According to the multivariate analysis, major, year of class, place of origin and a mother's education level are significantly associated with health-related knowledge in Chinese vocational college students.

Conclusions: Health education and health promotion efforts are encouraged to improve the level of healthrelated knowledge in this population. Attention and efforts to improve health-related knowledge of Chinese vocational college students who come from rural areas, whose mothers have a lower level of education, who are in non-medicine majors and during the first few years of vocational college is warranted.

\section{INTRODUCTION}

Health literacy is defined as 'the degree to which individuals have the capacity to obtain, process, and understand basic health information and services needed to make appropriate decisions'. ${ }^{1}$ The prevalence of limited health literacy is high among almost all populations including adolescents and young adults, ${ }^{2}$ middle-aged adults, ${ }^{3}{ }^{4}$ older adults ${ }^{3}$ and patients. ${ }^{5}$ Limited health literacy has been associated with adverse health outcomes $^{6}$ and huge financial burden. ${ }^{7}$ Health literacy has been shown as a stronger predictor of health status than any other socioeconomic status factors. ${ }^{8} \quad 9$ Therefore, improving the level of health literacy has

\section{Strengths and limitations of this study}

- The findings of this study added evidence into the limited literature on health-related knowledge among vocational college students.

- The sample size of this study ensures the statistical power to draw the conclusion.

- The cross-sectional design limits the ability to conclude casual inference.

- Our results are not representative to all vocational college students in China.

- The survey is based on self-reported data.

been put forward as an important action to promoting health. ${ }^{1011}$

To date, most evidence on the prevalence and consequences of health literacy is based on studies from developed countries. A previous investigation showed that a low-income population had a lower average level of health literacy than a high-income population. ${ }^{2}$ Thus, the prevalence of limited health literacy would be lower and the research is urgently warranted among developing countries. In China, though the government has published policies to improve the health literacy of citizens, ${ }^{12}$ the prevalence of adequate health literacy is still at a low level. In addition, the research on health literacy and its predictors is extremely limited so far. ${ }^{13} 14$

Adolescence is the stage with the greatest learning potential and influence from the family, school and society, and the stage is critical for forming the framework of health literacy. According to limited evidence, children and adolescents experienced a low level of health literacy which affected their behaviours and health. ${ }^{15}$

On the basis of a school-based survey among vocational colleges in China, this study sought to investigate the level of health-related knowledge (one aspect of health literacy) among vocational college students, and to examine the potential predictors of health-related 
knowledge levels in this college population. Our findings are significant as they provide a direction for future efforts of health education and promotion for the Chinese government and agencies.

\section{METHODS}

\section{Subjects and setting}

A multistage stratified cluster random sampling method was utilised to sample the subjects. At the first stage, four higher vocational colleges were randomly sampled from all vocational colleges in Nanyang City, Henan Province, China. This study area is a relatively middle-to-high income area in China. In 2013, Henan Province ranked its gross domestic product (GDP) in the fifth place among all 31 provinces in China. Nanyang City ranked its GDP in the third place among 18 main cities in Henan Province. At the second stage, 3 years of class (1st, 2nd and 3rd year) in all majors (Medicine, Agriculture, Art, Science) were randomly sampled in all four colleges; thus, $3 \times 4 \times 4=48$ classes were selected. Then all the students in these classes $(\mathrm{N}=720)$ were surveyed. Finally, 708 students completed the survey yielding a response rate of $98.3 \%$. This study was approved by the Ethical Committee at Nanyang Medical College. The informed consent forms with the statement of the study objective and confidentiality agreement were completed by the students before the survey.

\section{Measures}

The 2008 Chinese Citizens Health Literacy Questionnaire was used to collect the data on health-related knowledge. ${ }^{16}$ This questionnaire was evaluated as being valid and reliable that the correlation coefficient was 0.948 and no collinearity was existed among different dimensions. ${ }^{17}$ The selection options for multiple choice questions in the questionnaire were restructured to allow it to be used for higher vocational college students. However, the contents of the questionnaire were identical to those in the standard version. The questionnaire includes 40 questions covering three sections of health-related knowledge, including basic knowledge (20 questions), healthy lifestyle and behaviour (15 questions), and basic medical skills (5 questions), and several questions about the approaches with which respondents access information on health-related knowledge. The Health Literacy for All Chinese Citizens-the Basic Knowledge and Skills (Trial Version) issued by the National Ministry of Health was used as the standard to judge the answers from the students on the health-related knowledge questions. ${ }^{18}$ Each correct answer was assigned a point of 1 , otherwise 0 . Thus, the full score of all health-related knowledge questions for each student was 40. According to the scoring system, a score of $32(80 \%)$ or above was defined as adequate health-related knowledge. ${ }^{16}$

The potential predictors of health-related knowledge were collected by using a self-administrated questionnaire, including demographic factors (age and gender), place of origin (urban or rural), major (Medicine, Agriculture, Art, Science), year of class (1st, 2nd, 3rd) and parental education (middle school or below, high school, college or above). The whole survey was conducted by eight trained interviewers. The interviewers reviewed the completed questionnaires immediately after the survey to ensure the quality of data collection. The data were entered separately by two persons to ensure the accuracy of the data entry.

\section{Statistical analysis}

The health-related knowledge scores were compared with potential risk factors using the $t$ test for two-group comparison and analysis of variance for multiple comparisons. Linear regression models were used to examine the association between risk factors and health-related knowledge scores. The binary models were first built for each risk factor with health-related knowledge scores, and risk factors with a $p$ value less than 0.20 were entered in the final multivariate linear models. All analyses were performed using SPSS V.18.0, and $\mathrm{p}<0.05$ was set as the significance level.

\section{RESULTS}

Characteristics of the study sample are described in table 1 . The average age is 21 years (range 17-25 years). The majority of the students are female and from rural areas. Both the mother's and father's education is primarily in middle school or below level. Since the clustering sampling is stratified by major and year of class, the students are equally distributed among the subgroups of these two variables.

\begin{tabular}{|c|c|}
\hline Variables & $\mathbf{N}(\%)$ or mean (SD) \\
\hline Age & $20.6 \pm 1.3$ \\
\hline \multicolumn{2}{|l|}{ Gender } \\
\hline Male & $244(34.5)$ \\
\hline Female & $464(65.5)$ \\
\hline \multicolumn{2}{|l|}{ Place of origin } \\
\hline Urban & $338(47.7)$ \\
\hline Rural & $370(52.3)$ \\
\hline \multicolumn{2}{|l|}{ Major } \\
\hline Medical science & $181(25.6)$ \\
\hline Agriculture & 179 (25.3) \\
\hline Human science & $183(25.8)$ \\
\hline Science & 165 (23.3) \\
\hline \multicolumn{2}{|l|}{ Mother's education level } \\
\hline Middle school or below & $437(61.7)$ \\
\hline High school & $161(22.8)$ \\
\hline College or above & $102(14.5)$ \\
\hline \multicolumn{2}{|l|}{ Father's education level } \\
\hline Middle school or below & $323(45.6)$ \\
\hline High school & 237 (33.5) \\
\hline College or above & 148 (20.9) \\
\hline \multicolumn{2}{|l|}{ Year of class } \\
\hline 1st year & $232(32.8)$ \\
\hline 2nd year & $240(33.9)$ \\
\hline 3rd year & $236(33.3)$ \\
\hline Total & 708 (100.0) \\
\hline
\end{tabular}


Among 708 college students in this study, only 10 (1.4\%) students correctly answered $80 \%$ or more of all questions in the questionnaire. The proportion of students answering correctly more than $80 \%$ of the questions were $3.7 \%, 13 \%$ and $35 \%$, respectively, for basic knowledge and concept, healthy lifestyle and behaviour, and basic medical skills sections. The summary, distribution and correct rates of overall and subsection health-related knowledge scores are shown in table 2. The overall score of health-related knowledge in this sample is 24.4 out of 40.0 . Among 40 questions, 14 (35\%) questions were answered with a correct rate from $30 \%$ to $60 \%$, and $13(32.5 \%)$ questions are with a correct rate from $60 \%$ to $90 \%$. Only $7(17.5 \%)$ questions have correct rates exceeding $90 \%$. The overall correct rate is approximately $61 \%$ for health-related knowledge scores.

The overall and subsections' (basic knowledge and concept, health lifestyle and behaviour, and basic medical skills) health-related knowledge scores are compared by characteristics (table 3). For overall health-related knowledge scores, the highest scores (higher level of health-related knowledge) were found among students who were female and from urban areas, in the last year of class, with Medicine major and a college or above level of parental education. Three subsection scores showed similar differences across the characteristics factors except for basic medical skills by year of class (the students from the first year of class reported the highest score on the basic medical skills section).

The results of multivariate linear regression models are summarised in table 4. Students in Agriculture $(B=-1.034$, $\mathrm{p}<0.001)$, Art $(\mathrm{B}=-0.763, \mathrm{p}<0.001)$ and Science major $(\mathrm{B}=$ $-1.522, \mathrm{p}<0.001)$, from rural areas, $(\mathrm{B}=-0.213, \mathrm{p}=0.039)$ reported a lower level of overall health-related knowledge compared to those in Medicine major and those from urban areas. Students in a higher year of class $(\mathrm{B}=0.418$, $\mathrm{p}=0.024$ ) and with a mother's higher education level (high school: $\mathrm{B}=0.372, \mathrm{p}=0.031$; college or above: $\mathrm{B}=0.914$, $\mathrm{p}=0.024$ ) experienced a higher health-related knowledge than those in a lower year of class and those with mother's education in middle school or below level. The predictors for each section of health-related knowledge are major, year of class and a mother's education level for basic knowledge and concept, place of origin and gender for healthy lifestyle and behaviour, and place of origin and year of class for basic medical skills.
According to the survey, the top three approaches to acquire health-related knowledge are through the internet, television and school-based health education programmes. The most desired ways to acquire health-related knowledge are school-based health education programmes, internet and health-related lectures.

\section{DISCUSSION}

In this vocational college student sample, only $1.4 \%$ of the students achieved an adequate level of health-related knowledge based on the national standard criteria. For the questions in the questionnaire, the correct rates of the questions in the questionnaire are approximately $61 \%$. According to the multivariate analysis, major, year of class, place of origin and a mother's education level are significantly associated with health-related knowledge in Chinese vocational college students.

In our survey, we used almost the same questions (with some modifications on formatting only) from the Chinese Citizens Health Literacy Questionnaire. ${ }^{16}$ Therefore, our results are comparable to those from the national survey in China. Compared to the prevalence of adequate health-related knowledge among the 15-25 year age group population $(8.4 \%),{ }^{18}$ the prevalence of adequate health-related knowledge in our study sample is only $1.4 \%$. By looking at the subsections of the health-related knowledge survey, the students show a lack of understanding of basic knowledge and concept $(3.7 \%)$ and healthy lifestyle and behaviour (13\%), and a relatively acceptable level of knowledge of basic medical skills $(35.0 \%)$. The difference should not be due to the variance of age between the two samples, because the health-related knowledge score was found to increase with the year of class. The lower percentage of adequate health-related knowledge in our sample may be because the college students in this study were from vocational colleges which usually recruit students with lower scores in the examination of high school graduation or a lower Grade Point Average during high school in China. The level of knowledge is lower for vocational college students than for students from regular colleges and universities. A study based on a survey among Chinese ordinary college students reported that approximately $38.4 \%$ of the students had adequate health-related knowledge and skills. ${ }^{14}$ The percentage is much higher

Table 2 Statistics and distribution of health-related knowledge score

\begin{tabular}{|c|c|c|c|c|c|c|c|}
\hline \multirow[b]{2}{*}{ Health-related knowledge } & \multirow{2}{*}{$\begin{array}{l}\text { Number } \\
\text { of items }\end{array}$} & \multirow{2}{*}{$\begin{array}{l}\text { Mean number of items } \\
\text { answered correctly } \\
\text { (SD) }\end{array}$} & \multicolumn{4}{|c|}{$\begin{array}{l}\text { Number of items by correct } \\
\text { rate, } \mathrm{N}(\%)\end{array}$} & \multirow{2}{*}{$\begin{array}{l}\text { Correct } \\
\text { rate, \% }\end{array}$} \\
\hline & & & $\leq 30 \%$ & $30-60 \%$ & $60-90 \%$ & $>90 \%$ & \\
\hline Basic knowledge and concept & 20 & $12.25(2.37)$ & $4(20.0)$ & $5(25.0)$ & $8(40.0)$ & $3(15.0)$ & 61.2 \\
\hline Healthy lifestyle and behaviour & 15 & 9.12 (2.19) & $1(6.7)$ & 7 (46.7) & 5 (33.3) & $2(13.3)$ & 60.8 \\
\hline Basic medical skills & 5 & $3.05(1.00)$ & $1(20.0)$ & $2(40.0)$ & $0(0.0)$ & $2(40.0)$ & 61.1 \\
\hline $\begin{array}{l}\text { Overall health-related } \\
\text { knowledge }\end{array}$ & 40 & $24.43(4.20)$ & $6(15.0)$ & $14(35.0)$ & $13(32.5)$ & 7 (17.5) & 61.1 \\
\hline
\end{tabular}


Table 3 Health-related knowledge score by characteristics

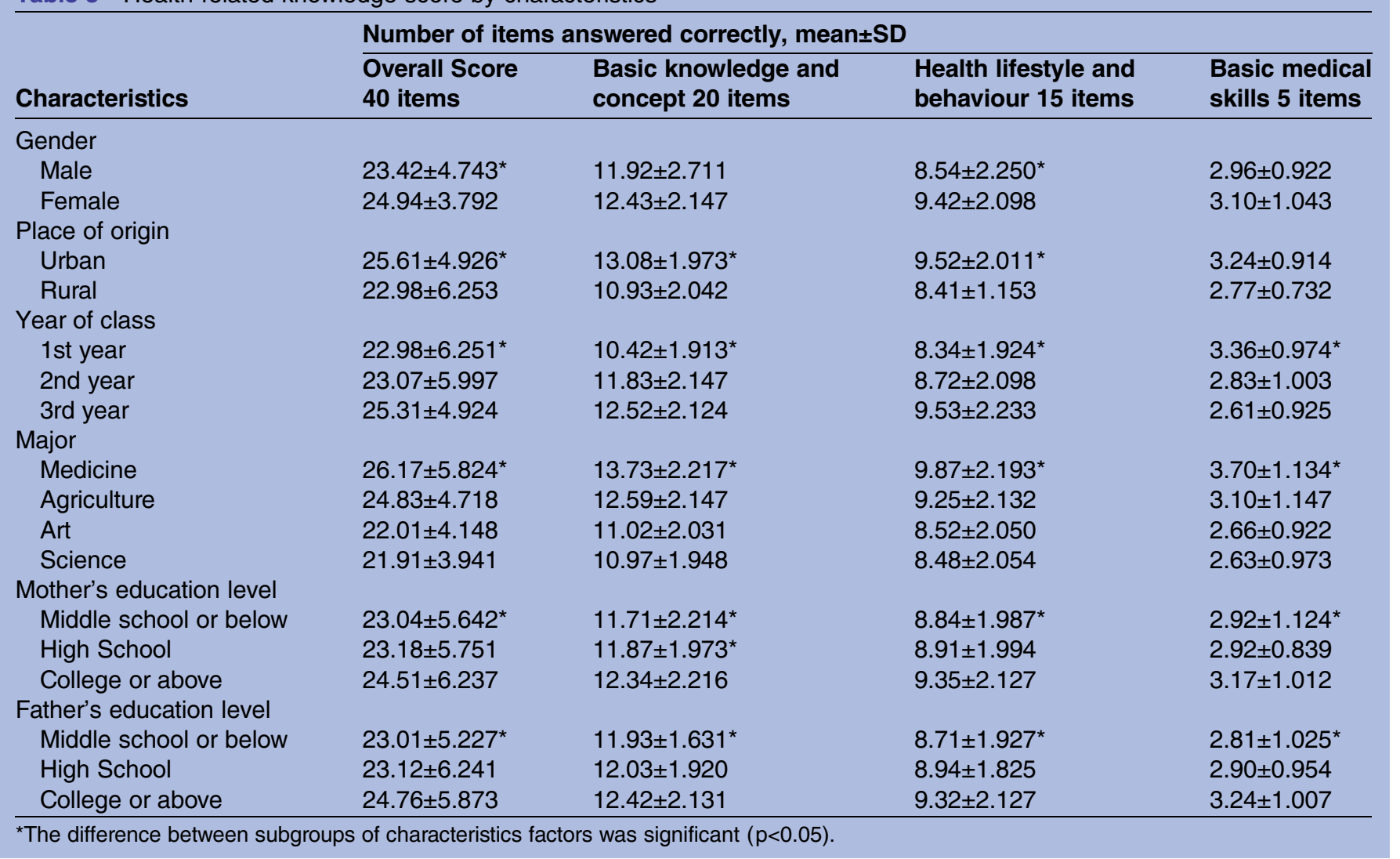

than that in our study. However, the questionnaire in this study is not the same as ours. In another survey based on college students in Beijing, China where many highly ranked Chinese universities locate, the proportion of students with adequate health-related knowledge is $24.8 \%$, and the percentages are $41.8 \%, 13.4 \%$ and $73 \%$, respectively, for basic health knowledge and concept, healthy lifestyle and behaviour, and basic medical skills. This survey is based on the same questionnaire as used in our survey, and the health-related knowledge level is obviously higher than that in our study. ${ }^{19}$ Therefore, the health-related knowledge in vocational college students in China is at a warning low level and needs to be significantly improved.

Major, class year, place of origin and a mother's education level are predictors of health-related knowledge level in our vocational college students. The findings are consistent with those in Zhao and Zhang study. ${ }^{20}$ For the health lifestyle and behaviour section, female students reported higher scores than male students, and this result is consistent with that in the survey among Beijing college students above. ${ }^{19}$ In our study, students in Medicine major have the highest level of health-related knowledge. This may be because medical students have a training background in health and medical knowledge and skills and they may have more chance to touch health knowledge and concepts than those in other majors. However, this inference cannot be assessed by our data due to the study design. The level of health-related knowledge is increased with year of class, which meant that education during college study might improve the health-related knowledge level among students. Therefore, health education and promotion programmes are warranted to be developed among vocational students in the campus. More attention should be paid to students coming from rural areas, where health education is usually inadequate for residents. According to this study, the mother's rather than the father's education level is positively associated with the level of health-related knowledge of college students. Mothers may play an important role in delivering health knowledge and skills to their children. Health education and promotion programmes might be warranted for mothers, especially for those with a low education level.

The results of our study should be interpreted in the light of several limitations. First, the cross-sectional design limits the ability to conclude a casual inference. However, most of the predictors included in this study are factors that have not changed over time, and thus the possibility of inverse causality is extremely low. Second, our survey was conducted among colleges only in Nanyang City. Our results are not representative of all vocational college students in China. In addition, we only measured one aspect of health literacy (health-related knowledge) in this study. More dimensions of health literacy are needed to be included in 
Table 4 Linear regression analysis $(\mathrm{N}=708)$

\begin{tabular}{|c|c|c|c|}
\hline Predictors & B Coefficient (95\% Cl) & SE & p Value \\
\hline \multicolumn{4}{|l|}{ Overall score } \\
\hline \multicolumn{4}{|l|}{ Major } \\
\hline Medicine & 0.00 & - & - \\
\hline Agriculture & $-1.034(-2.593$ to -0.725$)$ & 0.162 & 0.000 \\
\hline Art & $-0.763(-1.912$ to -0.014$)$ & 0.144 & 0.000 \\
\hline Science & $-1.522(-2.736$ to -0.023$)$ & 0.186 & 0.000 \\
\hline Year of class & $0.418(0.147$ to 1.893$)$ & 0.173 & 0.024 \\
\hline From rural & $-0.213(-1.075$ to -0.007$)$ & 0.107 & 0.039 \\
\hline \multicolumn{4}{|l|}{ Mother's education } \\
\hline Middle school or below & 0.00 & - & - \\
\hline High school & 0.372 (0.097 to 2.143$)$ & 0.312 & 0.031 \\
\hline College or above & 0.914 (0.354 to 2.757$)$ & 0.379 & 0.024 \\
\hline \multicolumn{4}{|c|}{ Basic knowledge and concept } \\
\hline \multicolumn{4}{|l|}{ Major } \\
\hline Medicine & 0.00 & - & - \\
\hline Agriculture & $-1.203(-2.914$ to -1.017$)$ & 0.173 & 0.000 \\
\hline Art & $-0.967(-2.142$ to -0.036$)$ & 0.151 & 0.000 \\
\hline Science & $-1.722(-3.132$ to -0.039$)$ & 0.194 & 0.000 \\
\hline Year of class & $0.531(0.316$ to 2.174$)$ & 0.225 & 0.009 \\
\hline \multicolumn{4}{|l|}{ Mother's education } \\
\hline Middle school or below & 0.00 & - & - \\
\hline High school & 0.421 (0.013 to 2.347$)$ & 0.347 & 0.021 \\
\hline College or above & $1.312(0.736$ to 3.125$)$ & 0.392 & 0.018 \\
\hline \multicolumn{4}{|c|}{ Health lifestyle and behaviour } \\
\hline From rural & $-1.128(-2.072$ to -0.413$)$ & 0.534 & 0.001 \\
\hline Female & $0.547(0.239$ to 2.074$)$ & 0.073 & 0.032 \\
\hline \multicolumn{4}{|l|}{ Basic medical skills } \\
\hline From rural & $-0.429(-1.314$ to -0.106$)$ & -0.114 & 0.015 \\
\hline Year of class & 0.517 (0.286 to 2.032$)$ & 0.143 & 0.027 \\
\hline
\end{tabular}

future studies. In the end, the survey was based on selfreported data. Although the data were collected by experienced trained interviewers and the quality control procedure was used throughout the data collection and entry, we have no ways to control the potential information bias from students. This study has several strengths. First, the findings of this study added evidence into the limited literature on health-related knowledge among vocational college students. In addition, the sample size of this study ensures the statistical power to draw conclusions. We used a multistage stratified cluster random sampling method in this study, and thus our results could be circulated among all vocational college students in this city.

\section{CONCLUSION}

The level of health-related knowledge among Chinese vocational college students is extremely low. Major, year of class, place of origin and a mother's education level are the predictors of health-related knowledge in this population. Health education and health promotion efforts are encouraged to improve the health-related knowledge level in this population. Attention and efforts to improve health-related knowledge of Chinese vocational college students who come from rural areas, whose mothers have a lower level of education, who are in non-medicine majors and during the first few years of vocational college is warranted.

Contributors WW and YH were the guarantor of integrity of the entire study and involved in the study design, manuscript preparation and manuscript editing. WW was involved in the study concepts. DZ gave the definition of intellectual content. WW, YH and DZ were involved in the literature research. AW and LL were involved in the clinical studies. JT, YM and NH were involved in the experimental studies and also involved in the data acquisition. YH, WW, $\mathrm{NH}$ and $\mathrm{JT}$ were involved in the data analysis. $\mathrm{YH}, \mathrm{WW}$ and $\mathrm{NH}$ were involved in the statistical analysis. DZ, NH and JT involved in the manuscript review.

Funding This study was funded by the Nanyang Foundation for Development of Science and Technology, China (Grant No: 2013GG055).

Competing interests None.

Patient consent Obtained.

Ethics approval This study was approved by the Ethical Committee at Nanyang Medical College.

Provenance and peer review Not commissioned; externally peer reviewed.

Data sharing statement No additional data are available.

Open Access This is an Open Access article distributed in accordance with the Creative Commons Attribution Non Commercial (CC BY-NC 4.0) license, which permits others to distribute, remix, adapt, build upon this work noncommercially, and license their derivative works on different terms, provided the original work is properly cited and the use is non-commercial. See: http:// creativecommons.org/licenses/by-nc/4.0/ 


\section{REFERENCES}

1. Ratzan S, Parker RM. National library of medicine current bibliographies in medicine: health literacy. Bethesda, MD: National Institutes of Health, U.S. Department of Health and Human Services, 2000.

2. Sanders LM, Federico S, Klass $P$, et al. Literacy and child health: a systematic review. Arch Pediatr Adolesc Med 2009;163:131-40.

3. Kutner M, Greenburg E, Jin Y, et al. The health literacy of America's adults: results from the 2003 national assessment of adult literacy. NCES 2006-483. National Center for Education Statistics 2006.http:// files.eric.ed.gov/fulltext/ED493284.pdf (accessed 14 Nov 2013).

4. Paasche-Orlow MK, Parker RM, Gazmararian JA, et al. The prevalence of limited health literacy. J Gen Intern Med 2005;20:175-84.

5. Morris NS, Grant S, Repp A, et al. Prevalence of limited health literacy and compensatory strategies used by hospitalized patients. Nursing Research 2011;60:361-6.

6. DeWalt DA, Berkman ND, Sheridan S, et al. Literacy and health outcomes. J Gen Intern Med 2004;19:1228-39.

7. Vernon JA, Trujillo A, Rosenbaum S, et al. Low health literacy: implications for national health policy: University of Connecticut, Department of Finance. 2007.

8. Parker RM, Ratzan SC, Lurie N. Health literacy: a policy challenge for advancing high-quality health care. Health Aff (Millwood) 2003;22:147-53.

9. Schillinger D, Grumbach K, Piette J, et al. Association of health literacy with diabetes outcomes. JAMA 2002;288:475-82.

10. Speros C. Health literacy: concept analysis. J Adv Nurs 2005;50:633-40.
11. US Department of Health aHS. Healthy People 2020. Health communication and health information technology. 2011. http://www. healthypeople.gov/2020/default.aspx (accessed 14 Nov 2013).

12. Pleasant A. Health literacy around the world: Part 1 health literacy efforts outside of the United States. Institute of Medicine, 2012.

13. Wang X, Guo H, Wang L, et al. Investigation of residents' health literacy status and its risk factors in Jiangsu Province of China. Asia Pac J Public Health 2013. doi: 10.1177/1010539513487012.

14. An W, Yu X, Zhang X, et al. A cross-sectional study on health-related knowledge and skills and its influencing factors among the Chinese college students. Chin J Epidemiol 2011;32:781-5.

15. DeWalt DA, Hink A. Health literacy and child health outcomes: a systematic review of the literature. Pediatrics 2009;124(Suppl 3): S265-74.

16. The first health literacy survey report among Chinese residents. The ministry of health center news propaganda. 2009. http://www.gov. cn/xwfb/2009-12/18/content 1490659.htm (accessed 25 Nov 2013).

17. Xiao L, Ma Y, Hu J, et al. Study on indicator system for evaluating the adult health literacy in China. Chin J Prev Med 2009;43:227-31.

18. Chinese citizen health literacy_basic knowledge and skills (Trial Version). 2008. http://www.gov.cn/gzdt/2008-02/05/content_884068. htm (accessed 25 Nov 2013).

19. Guo J, Du Z, Ma S. Survey of health literacy among college students in Beijing. Chin J Health Educ 2011;6:442-4.

20. Zhao Y, Zhang Y. Health literacy of medical students from technical and vocational colleges: a cross-sectional survey. Health Res 2012;32:450-2. 